\title{
Avoidance conditioning in two species of platy (Xiphophorus maculatus and Xiphophorus variatus)
}

\author{
EDWARD W. C. MCALLISTER* \\ Russell Sage College, Troy, N.Y. 12180
}

Two species of platyfish (Xiphophorus maculatus, blue platyfish, and Xiphophorus variatus, marigold platyfish) were given avoidance conditioning trials in an aquatic shuttlebox. While all blue platyfish reached a criterion of avoidance learning, only one marigold platyfish reached criterion learning. Results are discussed in terms of species-specific defense reactions (SSDRs).

The study and interpretation of results from avoidance learning studies in the laboratory has often overlooked the way animals behave in nature (Bolles, 1970). When comparative studies are carried out, some of the data do not meet expectations derived from current theories. Otis \& Cerf (1963) reported data from a study comparing avoidance learning in goldfish (Carossius auratus) and Siamese fighting fish (Betta splendens) of a dark-avoidance shuttle response with shock as a UCS. The results showed significantly better avoidance learning was shown by the goldfish over the Bettas. Otis \& Cerf (1963) stated: "We are unable to explain these findings at present. The difference in performance between these two species was unexpected. Actually, we expected the Bettas to be superior to the goldfish, as we have regularly observed that aggressive rats learned the shuttlebox response more rapidly than timid rats [p. 682]."

Bolles $(1970,1972)$ has suggested that such avoidance learning differences are explained by species-specific defense reactions (SSDRs). Bolles (1970) points out that animals in nature show very effective innate responses in a novel or dangerous situation. Generally, animals show flight, freeze, or some type of aggressive or pseudoaggressive behavior. In an avoidance learning situation, if the environment allows a SSDR, that will be the response with the highest probability of occurrence. If the avoidance response is the same response as the effective SSDR in the particular environment, very rapid avoidance learning should result. Further, as Bolles (1972) points out, the SSDR hypothesis is consistent with defensive behavior in the wild, where the animal cannot afford to "learn" to avoid danger.

The present study investigates avoidance learning in two species of platy: the blue platy (Xiphophorus maculatus) and the marigold platy (Xiphophorus variatus). Although platyfish are generally considered to be peaceful aquarium fish (Kallman, 1970), it was noted in the laboratory that the marigold platyfish were more

*Requests for reprints should be sent to Edward McAllister, Department of Psychology, Russell Sage College, Troy, New York 12180. This paper is sponsored by Ronald Ley, who takes full editorial responsibility for its contents. aggressive and active than the blue platyfish. Since these were the same behavioral traits noticed in the Otis \& Cerf (1963) study with goldfish and Bettas, it was decided to compare the avoidance learning in these two closely related fish.

\section{METHOD \\ Subjects}

The Ss were 14 platyfish, 2-3 in. long, acquired from a local dealer. Seven of the Ss were blue platyfish (Xiphophorus maculatus) and seven were marigold platyfish (Xiphophorus variatus). The platyfish were housed in 6-gal aquaria in the Russell Sage College Biopsychology Laboratory. The platyfish were transferred to the training apparatus by a small net.

\section{Apparatus}

A Lafayette student aquatic apparatus was used in this experiment. This apparatus is an aquatic shuttlebox composed of a 1-gal clear rectangular plastic tank, with a triangular hurdle $1 \frac{1}{2}$ in. high dividing the apparatus into two equal sections. A top fits over the tank and has one light $(14 \mathrm{~V})$ at each end of the tank to act as the CS. A Lafayette Program Timer 55000 controls the training rounds, so that the light (CS) goes on and is followed $9 \mathrm{sec}$ later by the shock (US) of $4 \mathrm{~V}$ ac. The shock and the light continue for $21 \mathrm{sec}$ or until the platyfish makes an escape response. The total time for each round is $60 \mathrm{sec}$.

\section{Procedure}

Each platyfish was placed in the experimental apparatus $1 / 2 \mathrm{~h}$ prior to training. The water in the experimental apparatus was from the same source as the water in the home aquaria and was maintained at the same temperature $\left(75^{\circ} \mathrm{F}\right)$ as the home aquaria. Training consisted of initializing the circuit for the round and was followed $15 \mathrm{sec}$ later by the onset of the light (CS). Nine seconds following the onset of the light (CS), the shock (US) of $4 \mathrm{~V}$ ac was initiated. Both the shock (US) and light (CS) continued for $21 \mathrm{sec}$, at which point the shock (US) and light (CS) terminated. Fifteen seconds later the system initialized for another round, so that each round lasted $60 \mathrm{sec}$. If the platyfish made an avoidance response while the light (CS) was on, the system was turned off and no shock (US) was applied. If the platyfish made an escape response, both the light (CS) and shock (US) were turned off immediately. The training rounds ran continuously. Training continued until the platyfish reached an avoidance learning criterion of five out of six avoidance responses or until 50 total rounds of training were completed. These parameters were determined by previous pilot work.

\section{RESULTS}

All of the blue platyfish reached the criterion of avoidance learning, while only one of the marigold platyfish reached the criterion. In fact, five of the seven marigold platyfish made very few avoidance responses at all.

An analysis of the conditioned avoidance responses using chi square revealed significant differences $\left(\chi^{2}=42.83, \mathrm{p}<.001\right)$ in avoidance learning between the marigold and blue platyfish. In addition, distinct differences in the behavior during the training sessions were observed. Marigold platyfish were much more 
Table 1

Conditioned Avoidance Learning in the Blue Platyfish (Xipho phorus maculatus) and the Marigold Platyfish (Xiphophorus variatus)

\begin{tabular}{ccccc}
\hline \multicolumn{5}{c}{ Blue Platyfish } \\
\cline { 2 - 5 } Ss & $\begin{array}{c}\text { Total } \\
\text { Total } \\
\text { Trials }\end{array}$ & $\begin{array}{c}\text { Avoidance } \\
\text { Responses }\end{array}$ & $\begin{array}{c}\text { Total } \\
\text { Escape } \\
\text { Responses }\end{array}$ & $\begin{array}{c}\text { Percent } \\
\text { Conditioned } \\
\text { Avoidance } \\
\text { Responses }\end{array}$ \\
\hline 1 & 29 & $11^{*}$ & 11 & 37.9 \\
2 & 16 & $10^{*}$ & 6 & 62.5 \\
3 & 13 & $8^{*}$ & 5 & 61.5 \\
4 & 16 & $6^{*}$ & 7 & 37.5 \\
5 & 9 & $6^{*}$ & 3 & 66.6 \\
6 & 15 & $6^{*}$ & 8 & 40.0 \\
7 & 12 & $5^{*}$ & 6 & 41.6 \\
Means & 15.71 & 7.43 & 6.57 & 49.66 \\
\hline & \multicolumn{5}{c}{\begin{tabular}{c} 
Marigold Platyfish \\
\hline 8
\end{tabular}} & 50 & 3 & 2 & 6.0 \\
9 & 42 & $18^{*}$ & 20 & 42.8 \\
10 & 50 & 0 & 48 & 0.0 \\
11 & 50 & 3 & 5 & 6.0 \\
12 & 50 & 1 & 3 & 2.0 \\
13 & 50 & 1 & 16 & 2.0 \\
14 & 50 & 13 & 32 & 26.0 \\
Means & 48.85 & 5.57 & 18.0 & 12.11 \\
\hline
\end{tabular}

*Reached criterion (criterion trials included)

active and aggressive than the blue platyfish. Upon presentation of shock, the marigold platyfish would dive to the bottom of the tank and then show rapid nose-down zigzag motions. The blue platyfish, on the other hand, never showed this type of response but showed only swimming responses. Such differences made escape by the blue platyfish more likely than escape by the marigold platyfish.

\section{DISCUSSION}

The results of this study were of the same order as found by Otis \& Cerf (1963) with goldfish and Bettas. The fish that were more aggressive were inferior to the less aggressive fish in obtaining a conditioned avoidance response of swimming away from the aversive environment (flight). However, while the results were surprising to Otis \& Cerf (1963), they are expected if SSDRs are assumed to be in operation. First, it had been observed in the home aquaria that the marigold platyfish showed more aggressive responses than did the blue platyfish. The marigold platyfish would often make rapid nose-down zigzag movements at the sides of the aquaria, while no blue platyfish were observed making such response patterns. This would indicate that an aggressive or pseudoaggressive SSDR would have a higher probability of occurrence for the marigold platyfish than for the blue platyfish. During feedings in the home aquaria, it was also observed that the marigold platyfish tended to eat at a lower depth than did the blue platyfish and that the marigold were much more active than the blue platyfish in chasing food, even though both types of fish had the same feeding schedule.

As mentioned above, the marigold platyfish would show this same kind of aggressive behavior when subjected to electrical shock during training. The marigold platyfish would often dive to the bottom and show a series of nose-down zigzag movements. Such responses made the possibility of an escape response lower, since escape was obtained only by swimming over the barrier. Those marigold platyfish that did make escape responses generally made them near the end of the shock time period after a great deal of movement. Blue platyfish were never observed to make these nose-down zigzag movements. Their responses were much more likely to be simple swimming responses away from the shock.

It appears that a different hierarchy of SSDRs exists within the two different platyfish. As Bolles (1970) states, SSDRs are generally flight, freeze, or threaten when a novel stimulus appears. These responses are supposed to be protective for the organism in the natural state. It seems that the blue platyfish have a high-probability flight response when novel or threatening stimuli are introduced and, therefore, rapidly acquire the conditioned avoidance response of swimming away. The highest probability response (SSDR) for marigold platyfish appears to be "threaten" responses rather than flight. Therefore, the marigold platyfish do not show the rapid avoidance learning shown by the blue platyfish, because of the nature of the response requirement. This finding supports Bolles's (1970) argument that the response requirement is the only really impressive parameter known and it is generally ignored in major behavior theories.

It is also interesting to note that these particular hierarchies of SSDRs might be predicted from the coloration patterns of the platyfish. The blue platyfish are a light metallic blue in color. In the aquatic environment, such coloration would allow a fish to disappear from a predator by swimming a relatively short distance, since this coloration would blend into the environment easily. The marigold platyfish, on the other hand, is yellow with orange-red markings. Flight would not be as successful for a platyfish with such coloration in the water environment, since they would be more easily seen than the blue platyfish. This could suggest that within the genetic structure of the platyfish there may be behavioral SSDRs tied to the genetic color patterns. Perhaps future research might document such a speculation.

\section{REFERENCES}

Bolles, R. C. Species-specific defense reactions and avoidance learning. Psychological Review, 1970, 77, 32-48.

Bolles, R. C. The avoidance learning problem. In Gordon Bower (Ed.), The psychology of learning and motivation: Advances in research and theory. Vol. 6. New York: Academic Press, 1972 .

Kallman, K. Enjoy your platys and swordtails. New York: The Pet Library, 1970.

Otis, L. S., \& Cerf, J. A. Conditioned avoidance learning in two fish species. Psychological Reports, 1963, 12, 679-682.

werboff, $J$ \& Lloyd, $T$. Avoidance conditioning in the guppy. Psychological Reports, 1963, 12, 615-618.

(Received for publication March 8, 1973.) 